lesions in which the effect of treatment is of most diagnostic value. It usually causes a prompt diminution in the symptoms, but, to be of significance, this effect should be considerable, and should involve both sets of symptoms, the local and general. It is a remarkable but certain fact that a considerable diminution in the symptoms of other kinds of tumours, and especially in the general symptoms, sometimes follows the administration of iodide. The effect is most frequent in gliomata - the growths that give rise to most diagnostic difficulty. Sometimes even the optic neuritis may lessen, but more often this is unchanged, and should put us on our guard.

In estimating the significance of the subsidence of the neuritis, we must remember that every intense inflammation, when it has reached its height, tends to subside into a cicatricial atrophy, although the tumour that has caused it continues to grow. We must not mistake this natural subsidence for the result of our treatment. But this difficulty can often only be met by waiting. If any of the symptoms return or increase, if any symptcm persists that would be readily influenced were the growth syphilitic, we must assume that this nature is not probable. The delay involved cannot be avoided, but it is a grave disadvantage, since the progress of surgery has so greatly increased the need not only for exact but for prompt diagnosis.

The chronic local meningitis of syphilis causes distinctive symptoms chiefly when it affects the base of the brain and damages the cranial nerves, or when, at the convexity, it implicates the motor region. The symptoms are such as indicate a surface lesion, and the absence of the signs of any considerable loss of function of the subjacent tissue, such as considerable compression would cause, is the chief distinction from a gumma in the same situation. Especially when the symptoms indicate a wide area of irritation with merely superficial damage, the diagnosis can be made with considerable probability. This focal meningitis is probably less frequent at the convexity than is a growth, and it is certainly less frequent there than it is at the base of the brain. In the latter situation the most important symptoms are due to the damage to the cranial nerves, and the most important diagnostic points are well known. The therapeutic test is available only in recent cases of meningitis. When the development of the new tissue into fibres has set in, this seems to go on in spite of treatment, and the inevitable cicatricial contraction may perpetuate the damage produced in the more active stage. In a case of focal meningitis that has lasted for some months, although it may afterwards be proved to be syphilitic in nature, the symptoms are generally influenced but little, and occasionally not at all, by antisyphilitic treatment, however energetic. The other forms of meningitis, interesting and important as they are, I am compelled to pass over.

(To be contrnued.)

\section{ON SOME OF THE RELATIONS} OF NEUROLOGY

\section{STRGERY AND DERMATOLOGY.}

Being an Abstract of the President's Address delivered at the Neurological Society of London, January 24 th, 1889.

Bx JONATHAN HUTCHINSON, F.R.C.S., F.R.S., LL.D., Emeritus Professor of Surgery at the London Hospital.

Mr. Hutchinson's address, after thanking the Society for the honour of electing him President, proceeded to deal with certain subjects in which surgery and dermatology were concerned in diseases of the nervous system. He mentioned a case which had recently come under his care in which a man, after the ordinary operation for piles, suffered from permanent incontinence of urine and fæces. The incontinence was attended by loss of sensation in the skin about the anus and complete paralysis of the sphincter, similar conditions being apparently present in the urethra. The history made it probable that this condition of paralysis had been present from within a day or two of the operation. After discussing the associated innervation of the two sphincters, attention was asked to the very common occurrence of inability to empty the bladder after the operation for piles, and the question proposed as to how such occurrences were to be explained.

The subject next considered was that of "dry mouth," for which the name "xerostomia" was proposed in substitution for that of " aptyalism." The cases which have recently been under the consideration of the Clinical Society, with some others, were briefly reviewed, and the whole question considered as an important illustration of the influence of the nervous system in controlling and entirely arresting the secretion of glands. It was suggested that what we see demonstrated in the mouth, in cases of "xerostomia," may probably occur in other regions and viscera, and that: there may possibly be a neurotic arrest of secretion of the liver, pancreas, testes, etc. Some remarks were made on the converse condition of excessive secretion of fluids into the mouth, or "hydrostomia." It was thought that this was much more frequently a symptom of aggressive disease of the nervous system than the opposite condition of dry mouth appeared to be. Attention was next asked to the nervous phenomena in Raynaud's disease, and to various cognate conditions in which the supply of blood to different parts of the skin was injuriously influenced through the nervous system. The chief subject-matter of the address was, however, the consideration of those diseases of the skin which should be classed as neurotic. Putting aside derangements of nutrition of the skin which might follow upon injuries, it was proposed to class the disorders referred to under three heads: first, those due directly to disease of the nerves themselves, or to some trophic influence exercised by them; secondly, those due to disturbances of the circulation produced through nerves; and, lastly, those in which the nervous system, although not being directly concerned, still took some share in the way of general reduction of tone. In the first, and by far the most definite, group, herpes and morphœa or scleroderma were the principal examples, and concerning both of these Mr. Hutchinson entered into considerable detail. Attention was asked, in reference to herpes, to the remarkable fact that while common zoster rarely occurred twice in the same place, there were forms of herpes of which the peculiarity was liability to recurrence. It was asserted that while arsenic very frequently caused zoster, it acted almost as a specific in preventing recurrences of the other forms. The theory was upheld that herpes zoster was always due to peripheral neuritis, which involved the end-organs; that it was, in fact, as had been long ago said, a neuritis attended by an eruption. It was suggested that one great difference between zoster and the recurrent forms consisted in the severity of the neuritis in the former, which disorganised the nerve affected, and thus prevented the possibility of its being again attacked. In dealing with the subject of scleroderma (morphœa) Mr. Hutchinson took first the localised form, remarking that it was very different, though perhaps not belonging to a wholly different class, from that in which the affection was symmetrical, diffused, and, in greater or lest degree of severity, universal. He repeated an assertion which he had made, he said, many years ago, that all the main facts which were true as regards the development and evolution of zoster were true as regards morphœe. He held that it was certainly located, and in all probability produced through nerves. Its remarkable differences from zoster were its slowness of evolution and its long persistence, taken together with the fact that it was not at all uncommon to find it affecting several parts of the body and limbs at the same time. He believed that its earliest manifestation was always in the form of a cluster of spots, and that the large patches often seen at a later stage were always due to a confluence of these. He drew attention to the circumstance that fascia, muscles, and bones were not infrequently affected together with the skin, whilst comparatively little loss of sensation attended the changes. He thought it highly probable that the vasomotor filarents distributed in conjunction with those for motion and sensation were the parts primarily affected. The remarkable defects in the subsequent nutrition and growth of the parts involved were illustrated by photographs and drawings. Respecting the condition known as hemiatrophy of the face, it was contended that it was always the consequence of morphœa affecting the fifth nerve, and that it was not strictly an atrophy, but an arrest of development to be explained by the fact that the disease had occurred in early life before the parts had attained their full growth. A number of portraits were shown to illustrate the remarkable similarity of appearance in different examples of this singular condition. Some remarks next followed on the general principles which should guide us in determining whether any given 
disease was of neurotic origin or otherwise, and the need for increased caution in suggesting such origin was strongly enforced. Diseases of the skin directly due to nerves should, it was contended, always display certain definite features as regards the distribution of their patches. These patches ought always to be racemose or corymbiform. The coalescence of such spots might produce a long oval patch, but such patch ought always to be more or less irregular at its edge, and would almost always be attended by outliers. No eruption produced directly by nerves could possibly assume a rounded form. The terms "areate" and " circumscribed" could never be applicable to disorders of nutrition located by the filaments of nerves. Under this rule it was held that such diseases as alopecia areata and leucoderma were certainly not of neurotic origin. A second rule was that disorders originated by nerves never spread serpiginously - that is, they did not creep at their edges by infection of adjacent parts, as lupus, psoriasis, and leucoderma, with many others, so conspicuously did. On account of the slowness of its evolution, and the difficulty in making sure in its early stages of its precise limits, mistakes had occurred in respect to scleroderma on this point, and in not a few cases it had been asserted that it spread at its edges. That in a general way such tendency to spread was conspicuously absent there could not be the slightest doubt.

Hebra's observation as to the occasional corymbiform arrangement of the pustules in variola was next adverted to, and with it were mentioned the disease described by Dr. Duhring under the name of "dermatitis herpetiformis" and certain forms of lichen ruber, and of some syphilides which might also assume the corymbiform arrangement. It was admitted to be possible that in many diseases not primarily affecting the nervous system a tendency to peripheral neuritis might exist, which would explain the peculiar arrangement of the foci of inflammation in the skin.

The question was next asked Whether any disease produced by the nerves could be arranged in lines or streaks? and in reference to this the very remarkable conditions presented in congenital ichthyosis in streaks were discussed. Although these streaks bad been assumed to be neurotic, there were, it was remarked, great difficulties in accepting such a theory. The streaks often did not follow the course of any known nerves, nor was it easily comprehensible that the transit of a nerve-trunk deeply placed under the skin should evoke any phenomena along its course. It was admitted that the explanation of these congenital streaked eruptions was extremely difficult. Their arrangement on the walls of the chest and abdomen were often so extremely like that of zoster that Mr. Hutchinson said he had himself many years ago ventured the crude suggestion that they might be due to intra-uterine herpes.

At the conclusion of the address a number of drawings were exhibited illustrating various points which had been adverted to. With them was shown a very remarkable, and it was believed unique, skull, in which all the bones on one side of the head showed exostoses, with other evidences of overgrowth, of which on the opposite side there was not the slightest trace. In this specimen the right half of the jaw, as well as the bones of the skull, was affected, the state of hyperostosis ending precisely at the symphysis. Of this remarkable unilateral asymmetry it was suggested that two explanations were alone possible-either that the disturbances of nutrition were located by the distribution of the fifth nerve, or that they were due to some influence exerted probably during fœtal development. If the latter, nothing was known as to its precise nature, and the former appeared the most probable. A contrast was suggested between the condition of unilateral overgrowth exhibited in this skull and the cases of unilateral undergrowth in the so-called hemiatrophy of the face.

OPHTHALMIA in Schools.-At a recent meeting of the Managers of the Central London School District a communication was read from the Local Government Board concurring in the Board's decision to make temporary provision for children suffering from ophthalmia, and expressing their opinion that the structural changes indicated by Dr. Bridges and Mr. Smith were absolutely needed before the school could be brought into a satisfactory condition. The Board referred to a letter of April 13th, 1875, in which suggestions were made for the proper treatment of the children. In the course of the discussion that followed, $\mathrm{Mr}$. Searle, the vice-chairman, said that from about the year 1875 up to 1885 the number of children suffering from the disease was reduced from 345 to 84 , but since then the cases had risen very considerably. The letter of the Local Government Board was referred to the special ophthalmic committee.

\section{CHOLERA AND CHEMISTRY; OR THE INFLU- ENCE OF CHEMISTRY ON MEDICAL SCIENCE, AS ILLUSTRATED BY CHOLERA. ${ }^{2}$}

Bx WILLIAM SEDGWICK, M.R.C.S.ENG., President of the Society.

THE influence of chemistry on medical science has seldom, if ever, failed to lead to satisfactory results when the attempted progress has been strictly limited to the high road of chemical analysis, and when the by-ways of chemical assumption have been resolutely shunned; for, if the mind has been previously unbiassed by chemical assumptions, there can be no doubt that the evidence supplied by chemical analysis may be safely accepted and relied on in the scientific investigation of disease. When, for example, the medical profession had fully recognised the great fact that prolonged suppression of urine could occur during choleraic collapse without being followed by any symptoms of uræmic poisonsoning, it was for many years afterwards assumed that urea continued to be formed, and that it was vicariously disposed of in the flux from the stomach and bowels. When, later on, and in accordance with the unimperchable evidence of chemical analysis, it had been admitted that the absence of uræmic poisoning in cholera is due to the arrested formation of urea, the tendency to wander off into the by-ways of chemical assumption appears to have been too strong to be resisted; for, although it had been clearly demonstrated that this prolonged suppression of urine without symptoms of uræmic poisoning is met with in a very large number, and in a very large variety, of cases in which there is collapse closely analogous to that of cholera, and in which there could be no specific blood-poison capable, as was alleged in the case of cholera, of shutting off the blood from access to air in the lungs, yet the same tendency to substitute chemical assumption for facts which not only could be, but which had been, demonstrated by chemical analysis was still too strong to be withstood. The effect of the tendency in this case was to lead to what may be referred to as nne of the most remarkable series of assumptions in the history of medical science; for, in order to explain an alleged deficiency in the supply of oxygen to the blood, it was assumed that there was a blood-poison, which was supposed to produce mordid contraction of the pulmonary arterioles, and that, in consequence of such contraction, the aëration of the blood was checked. It was not until nearly two years after the production of my paper on the "Chemical Pathology of Respiration in Cholera," in which $M$. Doyère's analyses were for the first time made fully known to the medical profession in this country, that the author of this theory referred to the evidence of anyone who had chemically analysed the expired air, and who had consequently been able to demonstrate that the proportion of oxygen absorbed in typical cases of choleraic collapse, instead of being relatively less, is, on the contrary, always in excess of the carbonic acid eliminated. It has since been admitted, shortly before the close of the year 1887, that, as regards the pulmonary interchange of gases during collapse, there " is a more or less considerable diminution of the amount of carbonic acid exhaled, in proportion to the volume of oxygen absorbed by the blood." This admission, which has been long delayed, is irreconcilable with the theory of defective oxygenation of the blood resulting from the specific effect of a blood-poison; and, although an attempt has been made to lessen the force of the evidence adduced by fresh chemical assumptions in which it has been suggested that " these exact observations (of $M$. Doyère) indicate that abnormal chemical changes take place in the blood and tissues of cholera patients," and that "a portion of the oxygen enters into combination with some abnormal products, forming compounds which, as it were, take the place of carbonic acid," yet they are as much without any analytical evidence in their favour as was this author's previous assumption, which theoretically connected the arrested formation of the chief constituents of bile and urine with a relative deficiency of oxygen in the blood.

1 Abstract of the Presidential Address delivered at the fifty-eight Annual Meeting of the Harveian Society of London, January $17 \mathrm{th}, 1889$. 